\title{
Dynamic characteristics of an automotive fuel cell system for transitory load changes
}

\author{
Rabbani, Raja Abid; Rokni, Masoud
}

Published in:

Sustainable Energy Technologies and Assessments

Link to article, DOI:

10.1016/j.seta.2012.12.003

Publication date:

2013

Link back to DTU Orbit

Citation (APA):

Rabbani, R. A., \& Rokni, M. (2013). Dynamic characteristics of an automotive fuel cell system for transitory load changes. Sustainable Energy Technologies and Assessments, 1(1), 34-43.

https://doi.org/10.1016/j.seta.2012.12.003

\section{General rights}

Copyright and moral rights for the publications made accessible in the public portal are retained by the authors and/or other copyright owners and it is a condition of accessing publications that users recognise and abide by the legal requirements associated with these rights.

- Users may download and print one copy of any publication from the public portal for the purpose of private study or research.

- You may not further distribute the material or use it for any profit-making activity or commercial gain

- You may freely distribute the URL identifying the publication in the public portal

If you believe that this document breaches copyright please contact us providing details, and we will remove access to the work immediately and investigate your claim 
Rabbani A. and Rokni M., 2013, "Dynamic characteristics of an automotive fuel cell system for transitory load changes", SETA (Sustainable Energy Technology and Assessment), Vol. 1, pp. 34-43.

\title{
Dynamic characteristics of an automotive fuel cell system for transitory load changes
}

\author{
Abid Rabbani and Masoud Rokni* \\ Thermal Energy Section, Department of Mechanical Engineering, Technical University of \\ Denmark, 2800 Kgs. Lyngby, Denmark.
}

\begin{abstract}
A dynamic model of Polymer Electrolyte Membrane Fuel Cell (PEMFC) system is developed to investigate the behaviour and transient response of a fuel cell system for automotive applications. Fuel cell dynamics are subjective to reactant flows, heat management and water transportation inside the fuel cell. Therefore, a control-oriented model has been devised in Aspen Plus Dynamics, which accommodates electrochemical, thermal, feed flow and water crossover models in addition to two-phase calculations at fuel cell electrodes. The model parameters have been adjusted specifically for a $21.2 \mathrm{~kW}$ Ballard stack. Controls for temperatures, pressures, reactant stoichiometry and flows are implemented to simulate the system behaviour for different loads and operating conditions. Simulation results for transitory load variations are discussed. Cell voltage and system efficiency are influenced by current density and operating temperature as well. Together, air blower and radiator consume $10 \%$ of the stack power at steady-state; nevertheless their power consumption could reach $15 \%$ during load surges. Furthermore, water crossover in the fuel cell has shown a significant impact on anode inlet flows, humidity and recirculation pump during these load changes. Also, amount of water saturation at cathode is found to be abruptly fluctuating and its removal from cathode is dependent on operating temperature and reactant stoichiometry.
\end{abstract}

Key words: Dynamic simulation, system modeling, fuel cell, PEMFC, water crossover, system control.

\section{Introduction}

Fuel cell systems have received substantial attention in recent years and research on these systems has drastically increased mainly due to their inherent virtues of clean and efficient mode of operation. Existing fuel cell systems are categorized based on the type of electrolyte and preferred operating conditions. Among various types of fuel cells, the Proton Exchange Membrane Fuel Cells (PEMFC) is currently the best choice for portable power generation due to its relatively low operating temperature, quick start-up, high power density and efficiency to name a few.

As a power source for automotive applications, PEMFC systems are usually subject to inflexible operating requirements when compared to stationary applications. These systems have to operate at varying conditions related to temperatures, pressures, power load and humidity. PEMFC dynamics are influenced by reactant flows, heat management and water content in the streams as well as within the fuel cell itself. All the auxiliary components, such as air and fuel supply system which include compressors and control valves, and the thermal control system which consists of heat exchangers, coolant pumps and air radiators need to be controlled for optimum operation of fuel cell when the system experiences varying load changes. Understanding the transient behaviour of a PEMFC therefore becomes very beneficial in dynamic modelling of these power modules at a system-level.

Many PEM fuel cell models have been developed in recent years. However, very few of these models are published on dynamic modelling of complete PEMFC systems along with their BoP. 
Most of the available literature focuses on individual components of these systems, mainly on the fuel cell stack. While, steady-state models of these systems are present in abundance. A generalized dynamic model for fuel cell stack is reported by Amphlett et al. [1]. Another bulk dynamic model used for developing a control system is presented by Yerramalla et al. [2]. A simplistic dynamic model based on cathode kinetics was developed by Ceraolo et al. [3]. Pukrushpan et al. [4] presented a transient dynamic model and elucidated the dynamic characteristics of water transport in PEM fuel cells. A complete PEMFC system model was developed by Pathapati et al. [5] which included the dynamics of flow and pressure in the channels. Hu et al. [6] represented a threedimensional computational PEM fuel cell model with comparison of different flow fields. In recent years, several improved models were published by Park and Choe [7] and Jia et al. [8] to investigate fuel cell transient electrical responses under various operating conditions.

Heat management in PEMFCs being a critical factor in its operations and performance is accounted for in open literature as well. Issues related to temperature dynamics are dealt and studied by Vasu and Tangirala [9], which could predict the effects of temperature and feed flows on system transient behaviour. Khan and Iqbal [10] proposed a transient model to predict efficiency in terms of voltage output, and a thermal model including heat transfer coefficients and energy balance for the stack. Shan and Choe [11] analysed the temperature distribution on fuel cells by developing a two-dimensional model. Another control-oriented thermodynamic model is also proposed by del Real et al. [12].Coolant control strategies were suggested by Ahn and Choe [13] after investigation of temperature effects on the system. Jung and Ahmed [14] developed a stack model based on realtime simulator in MATLAB/ Simulink environment and validated it with experimental setup of Ballard Nexa fuel cell. A thermal management system for a PEMFC was designed by Asghari et al. [15]. Influence of temperature on fuel cell's characteristics is also reported by Beicha [16].

The model presented in this study aims at analysis and investigation of a complete PEMFC system and studies its transient response to varying load and operating conditions. According to authors' literature survey, no studies have been conducted on system-level dynamic modelling of PEMFC system with all the necessary BoP components. Previous studies focus on transient response of fuel cell stack under different operating conditions; primarily on individual component analysis. Therefore, a need for a control-oriented dynamic system model is identified, which simulates a fuel cell stack under multiple varying operating conditions and changing auxiliary components outputs. Dynamic characteristics of PEMFC are also attributed to the heat management and water transportation that is scarcely reported in the open literature. Investigations for effects of heat exchangers on fuel cell stack performance and water crossover on anode recirculation operations are therefore selected to be one of the primary objectives here.

Thereby in the entirety of this study, a sizeable focus has been set to devise a dynamic model of the fuel cell stack, which accommodates the electrochemical, thermal, feed flow and water transportation models. A complete system is constructed in Aspen Plus Dynamics by incorporating all the essential auxiliary components and implementing control strategies in order to emulate a real PEMFC system. Effects of these controls and other components are also investigated in this work. A thermal management strategy has been designed and its dynamic impact on fuel cell stack has been reported for the first time. Analysis of water crossover in the fuel cell and its impact on anode recirculation operations has been conducted and suitable findings are reported here. Moreover, twophase characteristics of concerning material streams are determined which provide suitable insight to saturated water issues in the fuel cell stack. This study also takes into consideration the BoP, such as air blower, valves, coolant pumps and air radiator; making it a thorough tool for predicting PEMFC dynamics and to provide important information for the design of control strategies. 
In the current study, the focus is on complete system with all necessary auxiliary components and their effect on system performance rather than effect of individual component on the system. Thus, it differs substantially from previous studies in the sense that not only dynamics of the fuel cell stack are included but responses of all other auxiliary components are also incorporated by applying a detailed control strategy design.

\section{System overview}

Layout of the proposed PEMFC system is shown in Fig. 1. The system comprises a PEMFC stack, air compressor, humidifier, pumps, heat exchangers and radiator for the cooling circuit, flow valves and controllers. Compressed air, which is fed into cathode of the stack is cooled and humidified prior to its entrance. Pressurized hydrogen from storage tank is regulated by a control valve into the fuel cell anode. Since the stack is not operated at dead-end mode, a higher fuel stoichiometry is maintained. Unutilized fuel from anode exhaust is recirculated back to the feed stream via a recirculation pump, thus allowing the fuel to be humidified.

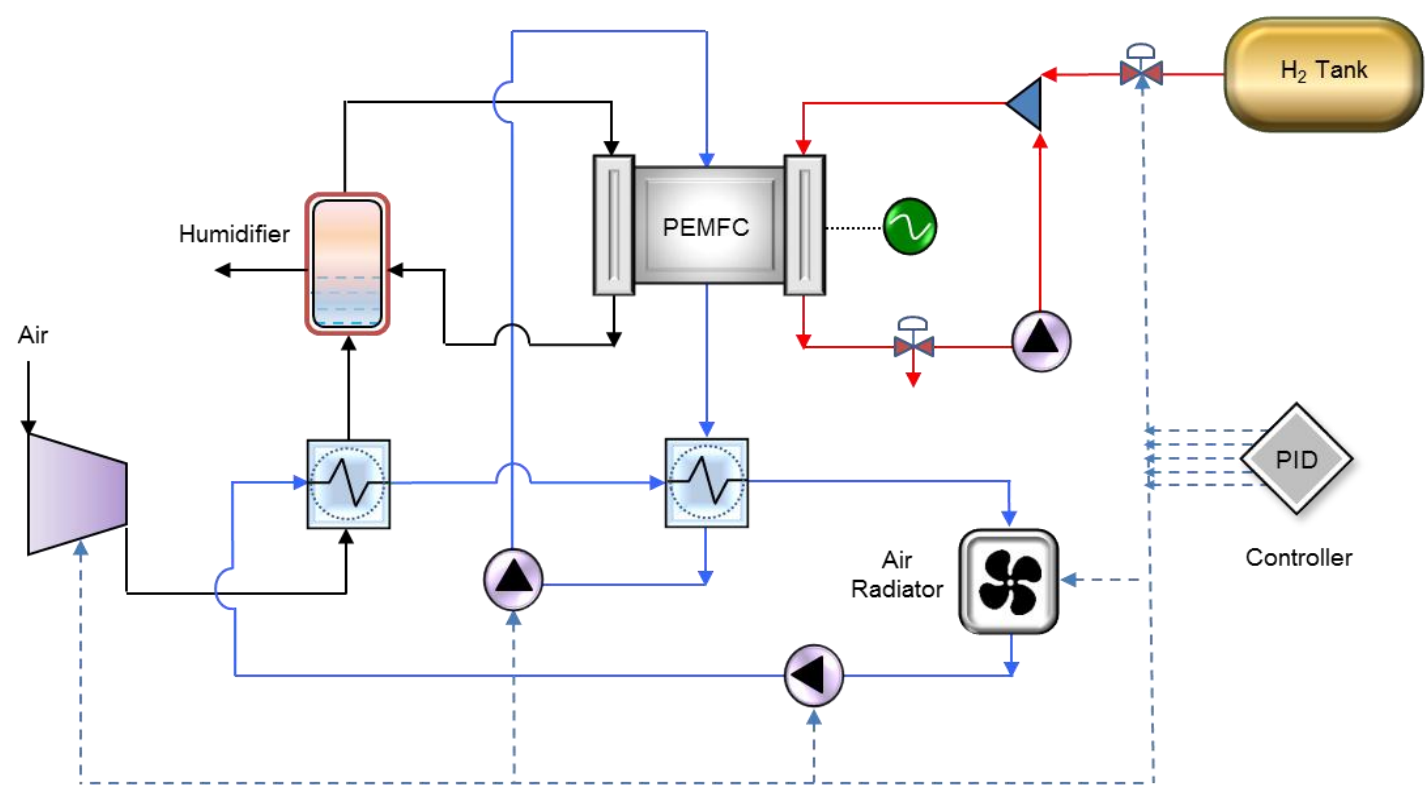

Figure 1. Schematic layout of a complete PEM fuel cell system with auxiliary components.

In order to have a steady-state operation, the fuel cell stack needs to be maintained at a constant operating temperature. Therefore, heat rejected by the stack is absorbed by a liquid coolant which circulates in a circuit associated with the stack and a heat exchanger. An external cooling loop, connected to the aforementioned heat exchanger, in turn cools the water in the internal circuit. This circuit also consists of a heat exchanger to precool air entering the fuel cell and an air radiator for heat rejection. Flow of water is regulated by pumps in the respective circuits.

In order to maintain reactant stoichiometry and fuel cell operating temperature at varying loads, PID controllers are deployed to regulate reactant and coolant flows. This emulates the behaviour of fuel cell in real time and helps in analysis of system response under varying operating conditions. Aspen Plus dynamics contains built-in PID controllers. These controllers collect data from various component inlet and outlets which are regarded as pressure, temperature and flow transmitters, and manipulate the corresponding components to reach the desired state. Due to this fact, current system responses and its behaviour are attributed to the formulated control strategy which is based on fuel 
cell stack limitations and recommendations by the manufacturer. Detailed control mechanisms are illustrated in subsection 2.6. Figure 1 only represents controllable connections initiating from the controller. In calculation as well as reality, the control unit collects information from various temperature, pressure and flow transmitters in addition to current and voltage data from the fuel cell. Here a simplified view of the system is presented.

\subsection{Fuel Cell stack}

A Ballard fuel cell stack [17] has been specifically adapted in the current study. The fuel cell stack contains 110 cells with a cell area equal to $285 \mathrm{~cm}^{2}$. Operating temperature of the stack is maintained around $60-70^{\circ} \mathrm{C}$ with a pressure range of $1.1-2.2$ bar. Maximum power produced from the described stack is $21.2 \mathrm{~kW}$ corresponding to a current of $300 \mathrm{~A}$; however it is generally operated at lower current ranges to attain higher efficiencies by reducing ohmic and concentration overpotentials within the fuel cell stack. This model, which is based on equations adopted by Hosseinzadeh and Rokni [18], contains some parameters influencing physical characteristics of the system, as well as on operating conditions and membrane properties. Some of these parameters which are obtained for the Ballard stack are shown in Table 1. Here, focus has been set to build up a system which meets the requirements of actual stack running under recommended conditions.

Table 1. Parameter estimation for Ballard Fuel cell stack

\begin{tabular}{ll}
\hline Parameter & Value \\
\hline Number of electrons transferred per mole of fuel, $n_{e}\left(\mathrm{~mol}_{e} / \mathrm{mol}_{\text {fuel }}\right)$ & 2 \\
Number of electrons for the reaction rate, $n_{e l}\left(\mathrm{~mol}_{e} / \mathrm{mol}_{\text {fuel }}\right)$ & 1 for cathode and 4 for anode \\
Internal current density, $i_{n}\left(\mathrm{~A} / \mathrm{cm}^{2}\right)$ & 0.002 \\
Symmetry factor, $\beta$ & 0.5 \\
Membrane thickness, $t_{m}(\mathrm{~cm})$ & 0.0183 \\
Density of the membrane-dry condition, $\rho_{d r y}\left(\mathrm{~g} / \mathrm{cm}^{3}\right)$ & 3.28 \\
Molecular weight of membrane, $M_{m}(\mathrm{Kg} / \mathrm{mol})$ & 1.1 \\
\hline
\end{tabular}
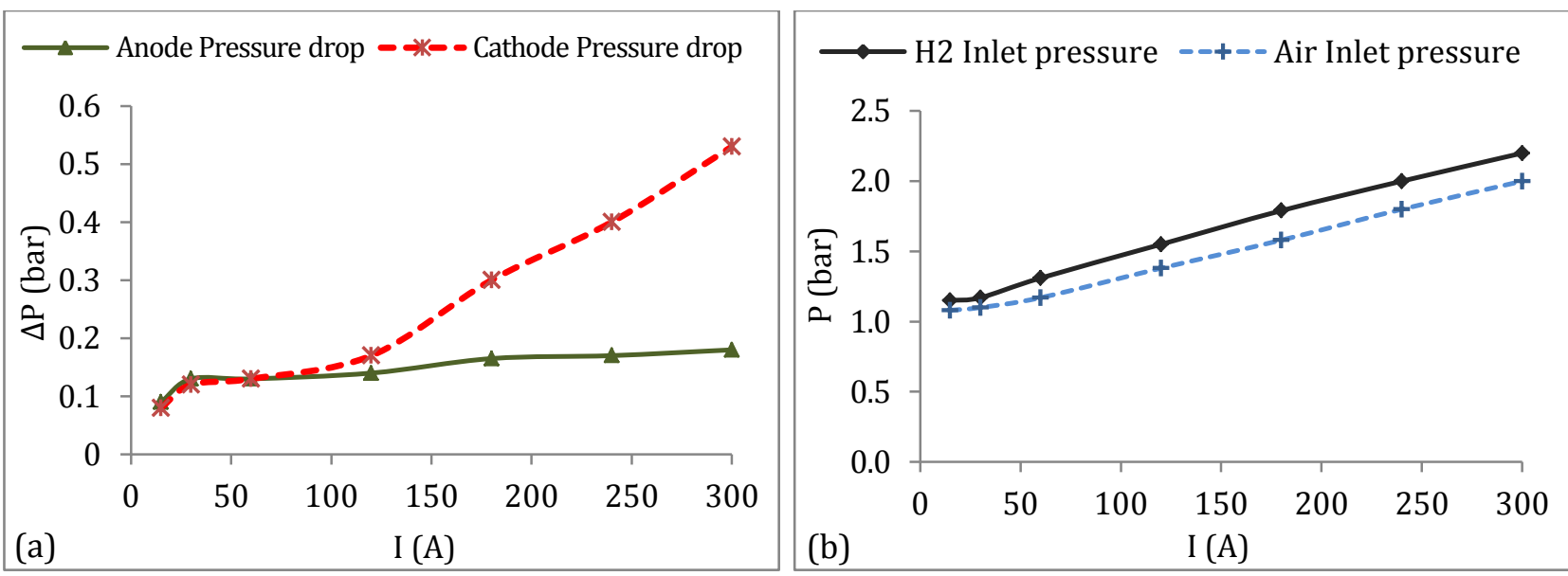

Figure 2. Design validation data from Ballard (a) Nominal pressure drop of reactants within the fuel cell, (b) Reactant inlet pressures corresponding to current drawn. 
During PEMFC steady-state operations, coolant pressure should be lower than reactant pressures whereas during start-up, coolant pressure may exceed reactant pressure. It is recommended to operate the anode at a higher pressure than the cathode. Ensuring that cathode pressure is lower than the anode pressure will minimize nitrogen crossover and improve cell stability. In a system with fuel recirculation, the consumption will be slightly above 1.0 stoichiometry as generally $1 \%$ to $2 \%$ of the flow will be required for purging. In the present study, purge occurrences are neglected. For a maximum service life and efficiency of the stack, Ballard suggests operating conditions within which the stack should operate [17], which are used in the current investigation. Recommended reactant inlet pressures and nominal pressure drops within the fuel cell stack are reported in Fig. 2.

\subsection{Humidifier}

Dehydration in fuel cell membrane is also a critical issue in PEMFC systems. In order to reduce ionic resistance in the fuel cell, a fully hydrated membrane is desired which enhances ionic crossover between the electrodes, as well as extends its life. Therefore, the reactants in PEMFC need to be humidified before entering the stack. In the proposed configuration, a humidifier is placed in conjunction of cathode inlet and exhaust, where it utilizes the water produced by chemical reaction inside the fuel cells to humidify inlet air. A simplistic energy and mass balance model is developed to cater for fuel cell cathode requirements. Although some empirical models could be considered, these vary over a wide range depending upon the types of humidifiers used. It is therefore assumed that inlet air is optimally humidified after passing through the humidifier. Relative humidity of air entering the cathode is arbitrarily set to $95 \%$ in the simulations. This assumption could be justified as it is very close to real operational conditions. On the anode side, fuel is humidified by means of water crossover through cell membrane and recirculation of anode exhaust into the inlet stream, thereby abandoning a need for separate humidifier. Moreover, it can be observed that water cross-over from cathode to anode through the membrane is adequate enough to raise the relative humidity in anode outlet to $100 \%$. This exhaust, when recirculated and mixed with inlet stream maintains the desired humidity levels at anode inlet, which is further discussed in results section.

\subsection{Reactant feed systems}

Auxiliary components such as blowers, pumps and valves regulate flows of material streams in PEMFC systems. For hydrogen feed, a valve is placed between the hydrogen tank and inlet manifold of anode which enables or disables the hydrogen supply. This regulatory valve adjusts high hydrogen pressure of the tank to the desired operating pressure of the fuel cell. Since the system does not operate on dead-end mode, the amount of hydrogen regulated by this valve equals the stoichiometric hydrogen required by the fuel cell. An air blower regulates the flow and pressure of oxidant into the cathode. The amount of stoichiometric oxygen for fuel cell reaction is manipulated by a controller which regulates the electrical power of the blower, thereby controlling the compression and air flow into the system.

\subsection{Heat Exchangers and thermal management system}

For heat management of the prescribed system, a network of heat exchangers and radiators is deployed. These heat exchangers extract heat produced by the cell stack and maintain the selected operating temperature which is essential for performance and durability of the fuel cell. Although heat exchanger models used here are predefined in Aspen Dynamics, some of the parameters have been assumed on the basis of media entering the hot and cold sides of these heat exchangers. The heat exchanger, which is connected to the internal cooling loop, has liquid water on both its hot and cold side. Therefore, a UA value of $1.0 \mathrm{~kW} / \mathrm{K}$ is assumed. Whereas, UA values for air pre-cooler 
and radiator are approximated to be $0.05 \mathrm{~kW} / \mathrm{K}$ and $0.3 \mathrm{~kW} / \mathrm{K}$ respectively. In performing the simulations, the pressure drop was assumed to be 0.05 on both sides of heat exchangers. The corrected LMTD is calculated in addition to the corresponding inlet and outlet temperatures of hot and cold streams.

\subsection{Pumps and Blowers}

In the above proposed system, air blower, anode recirculation pump and water pumps are one of the BoP components which are also regulated by the control system. Aspen Dynamics ${ }^{\mathrm{TM}}$ contains models of these units in its library as well. Since the nominal power of the PEMFC is only $21 \mathrm{~kW}$, mass flow rates of fuel and air are very low. For example, at an average load of $10 \mathrm{~kW}$, fuel and air flows are around $0.00014 \mathrm{~kg} / \mathrm{s}$ and $0.0088 \mathrm{~kg} / \mathrm{s}$ respectively. Therefore, very low values of isentropic efficiencies are suggested in this paper. The efficiency of a blower ranges from $15 \%$ to $48 \%$ in the calculations, depending on the air mass flow. Calculated pump efficiencies are also very low for the cooling water circuits and are determined to be around $70 \%$.

\subsection{Control System}

In order to have a stable and efficient operation, the system requires an effective control strategy to regulate system parameters and operating conditions. Typical proportional-integral (PI) controllers, which are widely used in industrial control systems, are employed to regulate different components and flow streams. Key parameters to be controlled in the proposed system are reactant inlet stoichiometries, inlet pressures, coolant inlet and operating temperatures of the stack.

Figure 3a shows fuel and air stoichiometries for the selected fuel cell stack which are proposed by Ballard and in Fig. 3b, recommended temperature difference between stack inlet and outlet is displayed.
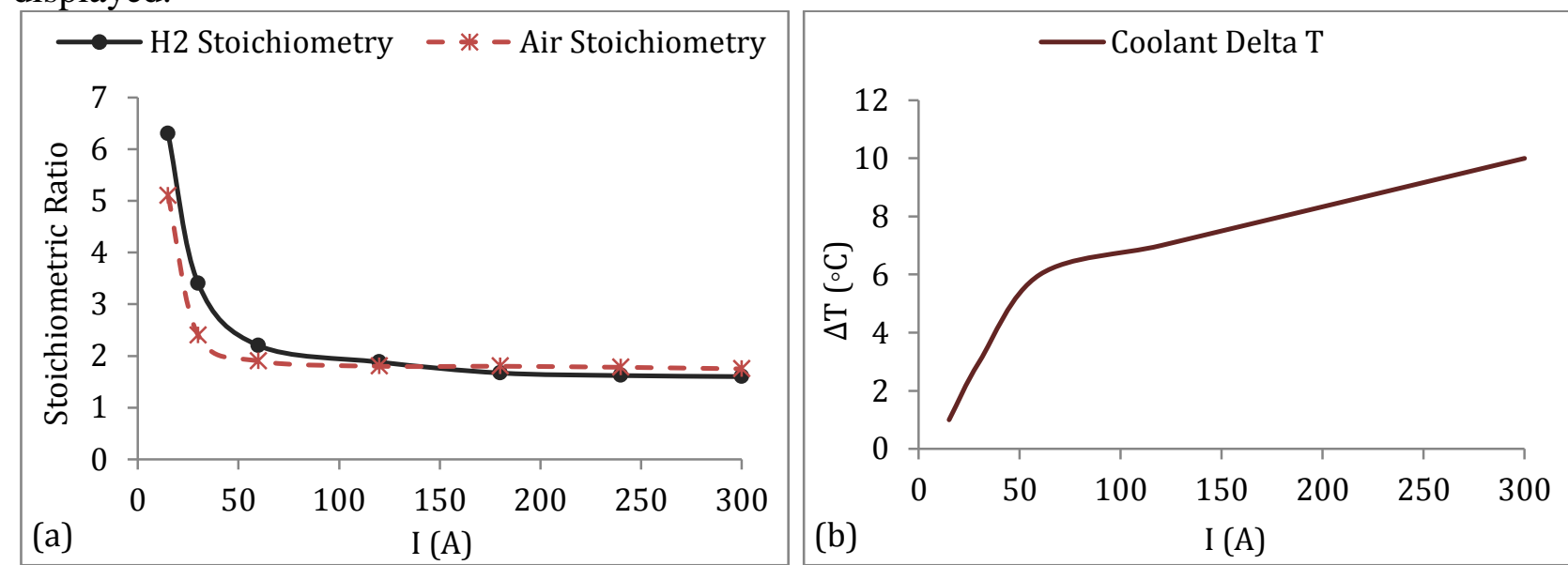

Figure 3. Recommended operating conditions by Ballard, (a) Reactant stoichiometry in the fuel cell, (b) stack inlet and outlet temperature difference maintained by coolant mass flow.

It can be seen that at low current loads, high amounts of excess reactant flows are desired. This is due to the fact that at low power consumption and low pressures, water is formed by reactions in cathode side of the cells and it needs to be ejected out of the stack, which is done by supplying high amounts of reactants. While the amount of oxygen consumed depends on the stack current, the amount of oxygen supplied to a fuel cell is directly related to the blower power. Therefore, an algorithm based on the above figure is developed to be the process variable for PI controller, which regulates blower power to maintain the desired oxygen ratio. Similarly, an algorithm for controlling 
hydrogen flow is devised along with a PI controller, which regulates the control valve opening for optimal fuel supply.

Thermal management in PEMFC systems is of vital importance, basically due to the fact that heat produced in the selected fuel cell cannot be dissipated by convection and radiation through the stack surface. A consistent and stable operation of around $70^{\circ} \mathrm{C}$ thus requires a liquid cooling system. Since the operating temperature of the fuel cell is not very high, a low temperature difference with the ambient requires having a large heat transfer surface. Thus, an efficient thermal control system becomes of substantial importance to ensure optimum system performance.

As shown in Fig.1, the cooling system for fuel cell consists of internal and external cooling circuits. Also mentioned earlier, the coolant mass flow rate defines the variance in the stack temperature or simply maintains the fuel cell operating temperature. In this case, temperature in the stack can be controlled by coolant flow rate which acts as an input signal and is adjusted by the PI controller. Based on data from Fig. 3b, equations defining stack temperature as a set-point for controller are developed. In addition, the controller simultaneously collects data from temperature transmitter at coolant outlet stream, which then changes the coolant flow accordingly by sending output signals to the driving pump. Employment of such algorithm in the system controller ensures a stable operation under normal steady-state conditions, however for system start-up scenario, a different approach is required.

Temperature of the coolant entering the stack can similarly be controlled by flow of water in the external circuit. Control signal to the associated pump regulates electrical power of the pump and hence the coolant inlet temperature into the stack. In a similar fashion, temperature of water in the external circuit is dependent on radiator fan speed. PI controllers are used to regulate the fan speed as well.

\section{Fuel cell modelling}

The characteristics of the PEMFC system described above are implemented in Aspen Plus Dynamics $^{\mathrm{TM}}$ which is a simulation tool for process modelling and energy system analysis. The program contains a vast library of components and controls for standard energy processes. The PEMFC stack model presented in this study is based on a model developed by Hosseinzadeh and Rokni [18]. Concentration losses are neglected in the present study, which is justified by the fact that the system does not run at such high current densities where the concentration overpotentials becomes significant. Models for fuel cell and humidifier are also implemented into the code and are based on adopted mathematical models describing the voltages, current densities and their dependence on operating pressures, temperatures and stoichiometric ratios of the reactant gases. This model which incorporates governing equations for cell electrochemical, polarization overpotentials, heat transfers and water diffusion across the membrane is implemented into ASPEN Plus Dynamics and system controls are implemented in order to ensure stable operation of the plant during load changes. Thermodynamic efficiency and net power of the system are determined by the current drawn and voltage produced by the stack. Total energy into the fuel cell is consumed by electrical power output, heat removed by the coolant, heat loss at the stack surface and energy stored by the stack itself. In the current model, a lumped thermal model proposed by Khan and Iqbal [10] is considered. The stack is regarded as a single thermal mass with a heat capacity. With the assumption of stack temperature being equal to coolant temperature at the outlet, heat exchanged with the coolant and hence stack operating temperature could be determined. Subordinate components in the BoP, i.e. anode recirculation and water pumps, air compressor, mixers and heat exchangers are simulated by using default mathematical models contained in Aspen 
Plus Dynamics library. Table 2 shows a standard set of equations which constitute the model used in the current study.

Table 2. Constitutive equations for PEMFC model.

Average cell voltage

Nernst equation

Theoretical cell voltage

Change in Gibbs free energy

Activation losses in PEMFC

Ohmic overpotentials

Ionic resistance in the cell

Membrane water content

Water vapour activity

Water profile inside cell membrane

Transfer coefficient for anode

Transfer coefficient for cathode

Exchange current density at anode

Exchange current density at cathode

Net water transportation through membrane
$V_{\text {cell }}=E-\eta_{\text {act }}-\eta_{\text {ohmic }}-\eta_{\text {conc }}$

$E=\frac{-\Delta \bar{g}_{f}^{0}}{n_{e} F}+\frac{R T}{n_{e} F} \ln \left(\frac{a_{H_{2} O}}{a_{H_{2}} a_{O_{2}}{ }^{0.5}}\right)$

$E=\frac{-\Delta \bar{g}_{f}^{0}}{n_{e} F}+\frac{R T}{n_{e} F} \ln \left(P_{H_{2}}{ }^{-1} P_{O_{2}}^{-0.5}\right)$

$\Delta \bar{g}_{f}^{0}=\left(\bar{g}_{f}^{0}\right)_{\mathrm{H}_{2} \mathrm{O}}-\left(\bar{g}_{f}^{0}\right)_{\mathrm{H}_{2}}-\frac{1}{2}\left(\bar{g}_{f}^{0}\right)_{\mathrm{O}_{2}}$

$\eta_{a c t}=\eta_{a c t, c}+\eta_{a c t, a}=\frac{R T}{\alpha_{c} F} \ln \left(\frac{i+i_{n}}{i_{0, c}}\right)+\frac{R T}{\alpha_{a} F} \ln \left(\frac{i+i_{n}}{i_{0, a}}\right)$

$\eta_{\text {ohmic }}=\left(r_{e l}+r_{\text {ion }}\right) \cdot i$

$r_{\text {ion }}=\frac{C_{1} \cdot\left[1+0.03 i+0.062 \cdot(T / 303)^{2} \cdot i^{2.5}\right]}{\left(\lambda_{\text {ave }}-0.634-3 i\right) \cdot \exp \left[C_{2} \cdot(T-303) / T\right]} \cdot t_{m}$

$\lambda_{\text {ave }}=0.043+17.18 a_{w}-39.85 a_{w}^{2}+36 a_{w}^{3}$

$a_{w}=P_{w} / P_{s a t}$

$\lambda_{\text {mem }}=\frac{\lambda_{c}-\lambda_{a}}{t_{m}} \cdot z+\lambda_{a}$

$\alpha_{a}=\beta \cdot n_{e l}$

$\alpha_{c}=(1-\beta) \cdot n_{e l}$

$i_{0, a}=n_{e l} \cdot F \cdot k_{a} \cdot \exp \left(\frac{(1-\beta) \cdot n_{e l} \cdot F \cdot E}{R T}\right)$

$i_{0, c}=n_{e l} \cdot F \cdot k_{c} \cdot \exp \left(\frac{-\beta \cdot n_{e l} \cdot F \cdot E}{R T}\right)$

$J_{\mathrm{H}_{2} \mathrm{O}}=2 n_{\text {drag }} \frac{i}{2 F}-\frac{\rho_{d r y}}{M_{m}} D_{\lambda} \frac{d \lambda}{d z}$ 


\begin{tabular}{ll}
\hline Water diffusion coefficient & $D_{\lambda>4}=10^{-6} \exp \left[2416 \cdot\left(\frac{1}{303}-\frac{1}{T}\right)\right]$ \\
& $\left(2.563-0.33 \lambda+0.0264 \lambda^{2}-0.000671 \lambda^{3}\right)$ \\
Fuel cell energy balance & $C_{t} \cdot d T / d t=\dot{P}_{\text {in }}-\dot{P}_{\text {out }}-\dot{P}_{e l}-\dot{Q}_{\text {loss }}$ \\
Faraday's law & $\frac{d N}{d t}=\frac{I}{n_{e} \cdot F}$ \\
\hline
\end{tabular}

\section{Results and discussion}

Simulations for the prescribed system were carried out and reliability of the suggested model is verified and corroborated against design validation data by [17] at different power loads. Model characteristics of the same system at various operating temperatures and power loads have been studied in Hosseinzadeh and Rokni [18]. Figure 4a represents adaptation of the devised model which corresponds to the polarization curve obtained from operational data associated with the given PEMFC stack. The calculated relative error shows a good agreement between the model and date provided. As suggested by the manufacturer, stack temperature range of $60-70^{\circ} \mathrm{C}$ has been used in simulations of the current system. Selection of other parameters and operating conditions is based upon Fig. 2 and Fig. 3.
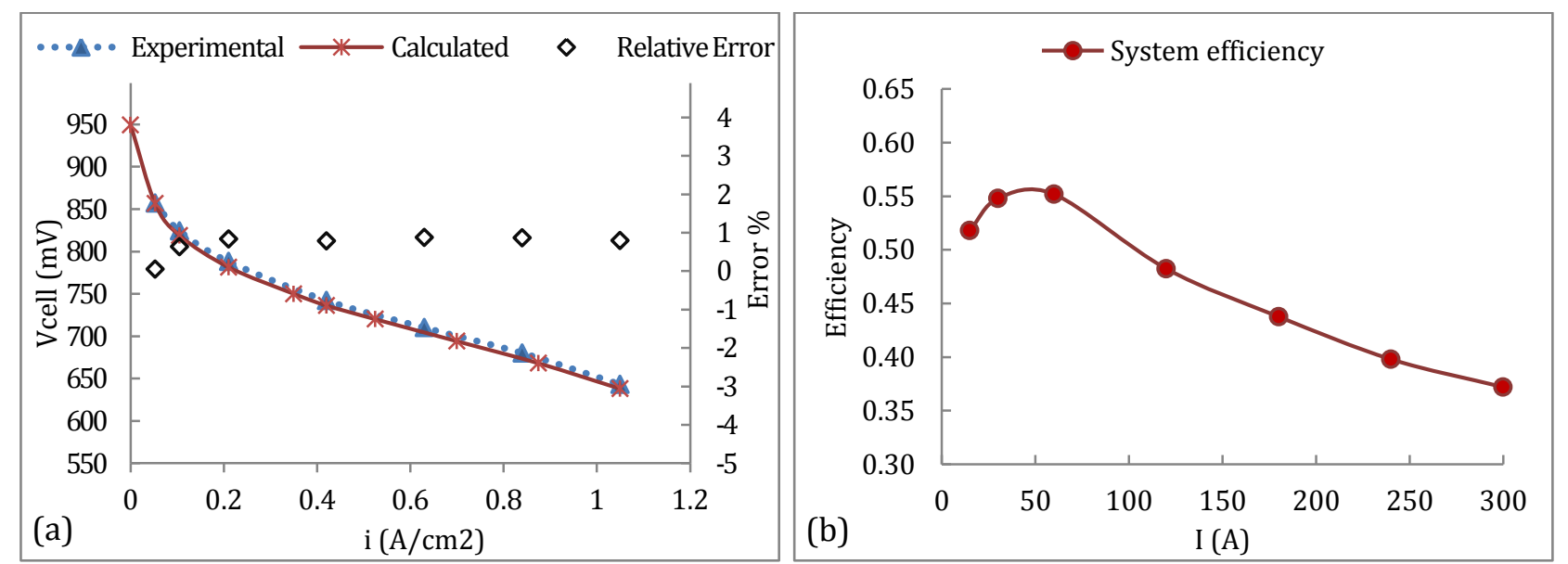

Figure 4. (a) Comparison of Ballard operational data and calculated polarization curves for PEM fuel cell with relative error, (b) Overall system efficiency profile at operating current range.

Fig. $4 \mathrm{~b}$ exhibits profile of overall system efficiency at corresponding currents. A general trend of decreasing efficiencies with increasing loads can be observed, which is characterised by an increase in ohmic overpotentials in the stack and high power consumption of BoP for cooling of the system. However an exception to the contrary can be noticed at very low currents, where high parasitic losses in BoP render the system efficiency to be lower as well. Nevertheless, higher stack efficiencies at low loads assist the system efficiency to be not as low when compared to that at higher currents.

Results for transitory effects under variable load changes (when a current corresponding to a specific power load is drawn from the stack and varied at any occurrence of time) are discussed below: 


\subsection{Cell voltage and temperature variations}

An instance of load change, when current is ramped from $60 \mathrm{~A}$ to $100 \mathrm{~A}$ at a rate of 20 amperes per second and vice versa, is presented in Fig. 5a and its effects on cell voltage are examined. It can be observed that the cell voltage reduces abruptly with current surge and vice versa. This decline in voltage potential at increase of current density is attributed to the cell overpotentials. However, it is also noticed that cell voltage is also a function of operating temperature and pressure. Since, pressures of the reactants are already regulated; here we will discuss temperature dependency of developed potential differences in the cell. Voltage increases with the elevation of operating temperature. This is due to fast reaction kinetics at the electrodes of individual cell sites when operating at higher temperatures. At the same instance of current ramp as more current is drawn; more heat is produced by the reactions at cell sites, thus elevating the stack temperature. Consequently, the voltage also increases after the initial dip and follows the decreasing profile with the stack temperature as it is controlled towards the desired operating temperature. The opposite could also be observed when the current is reduced back to $60 \mathrm{~A}$.
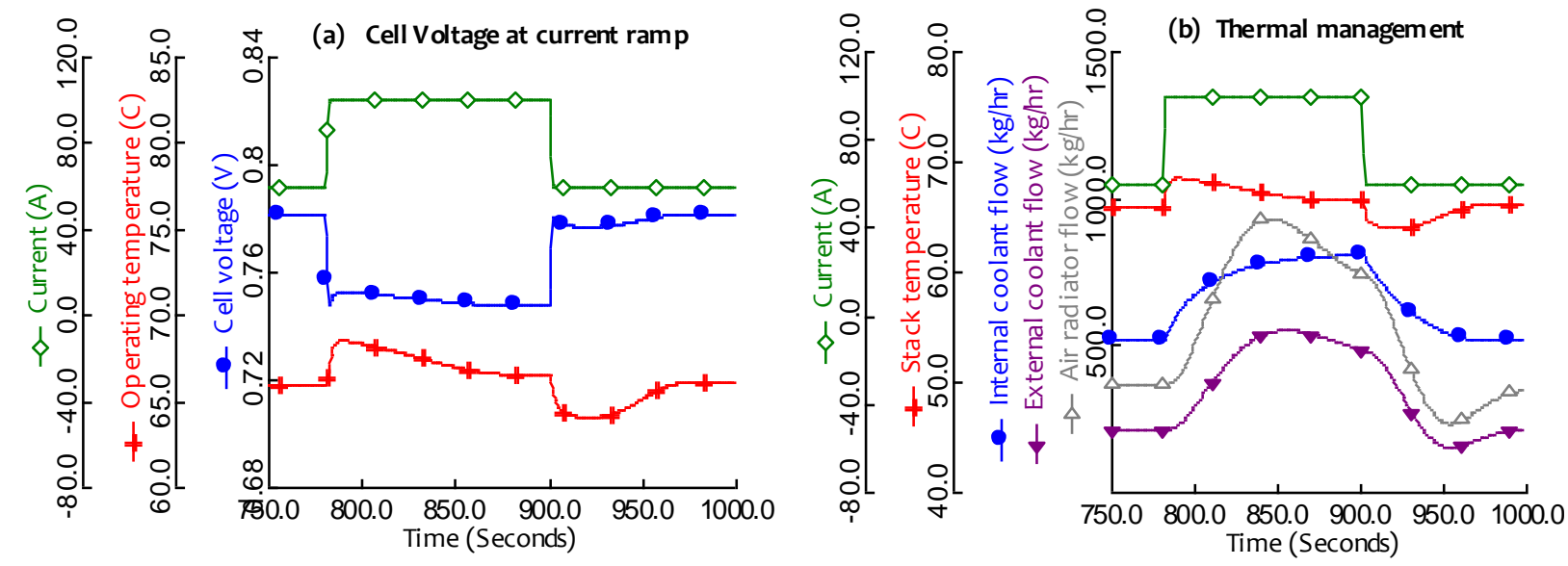

Figure 5. Current ramp-up from 60-100A and vice versa: (a) Changes in cell voltages and operating temperature, $(b)$ Changes in coolant flows to maintain the fuel cell operating temperature.

Since, temperature affects the voltage and overall system efficiency, it becomes important to have a stable operating temperature and therefore an efficient thermal management system. As can be seen in the Fig. 5b, coolant flow rates in both cooling circuits and an air radiator maintain the temperature of the stack, though it is very slow compared to the reaction kinetics affecting the stack voltage. Ramping of current increases the operating temperature of stack thereby actuating controls to contemplate this increase. Flow in the internal cooling circuit, which is coupled with the fuel cell stack is increased to extract heat and maintain the desired temperature difference between the stack inlet and outlet. Flow in the external cooling circuit is pumped up to retain the inlet temperature to $60^{\circ} \mathrm{C}$. Air flow in radiator is also increased to maintain temperature of external cooling loop around $50^{\circ} \mathrm{C}$ by rejecting the heat to the surroundings. Rate of coolant flows in respective streams is associated with the power consumed by coolant pumps and air radiator which ultimately affects the overall system efficiency. It is also observed that air radiator being a liquid-gas heat exchanger has the slowest reaction time out of the three. Since temperature controls are slow compared to electrochemical reactions, overall thermal control strategy has a fair impact on stack voltage which undergoes frequent load changes. 


\subsection{System efficiency and power consumption}

As can be seen in the Fig. 6a, when the stack current is altered from 60A to 100A, there is a reduction in system efficiency, mainly due to the associated voltage drop. Overall efficiency of the system is as much affected by air blower and radiator fan, as by the fuel cell stack itself. It can be observed that power produced by the stack increases with current drawn. Also, power consumed by auxiliary components increases, thereby reducing system efficiency from $55.5 \%$ to $50 \%$. Once decreased, there is an abrupt rise in efficiency due to increase in voltage and it fluctuates at around $50 \%$ mark due to slow temperature controls and fluctuating power consumption by air radiator.

Figure $6 \mathrm{~b}$ elaborates on power consumption in the system. Being a major consumer in the system, power consumption of air blower rises with increase in current and this incremental profile can be associated to the increased mass flow of air required to maintain oxidant stoichiometry in the fuel cell. After the initial rise, power consumption of air blower becomes constant; however the consumption graph of air radiator takes more time to become stable. This is due to the fact that flow in air radiator is manipulated to control the temperature and is a slow process. Together, air blower and radiator consume $10 \%$ to that of stack power, whereas a coolant and recirculation pumps account for $1.0-1.3 \%$ when operating at $60 \mathrm{~A}$.
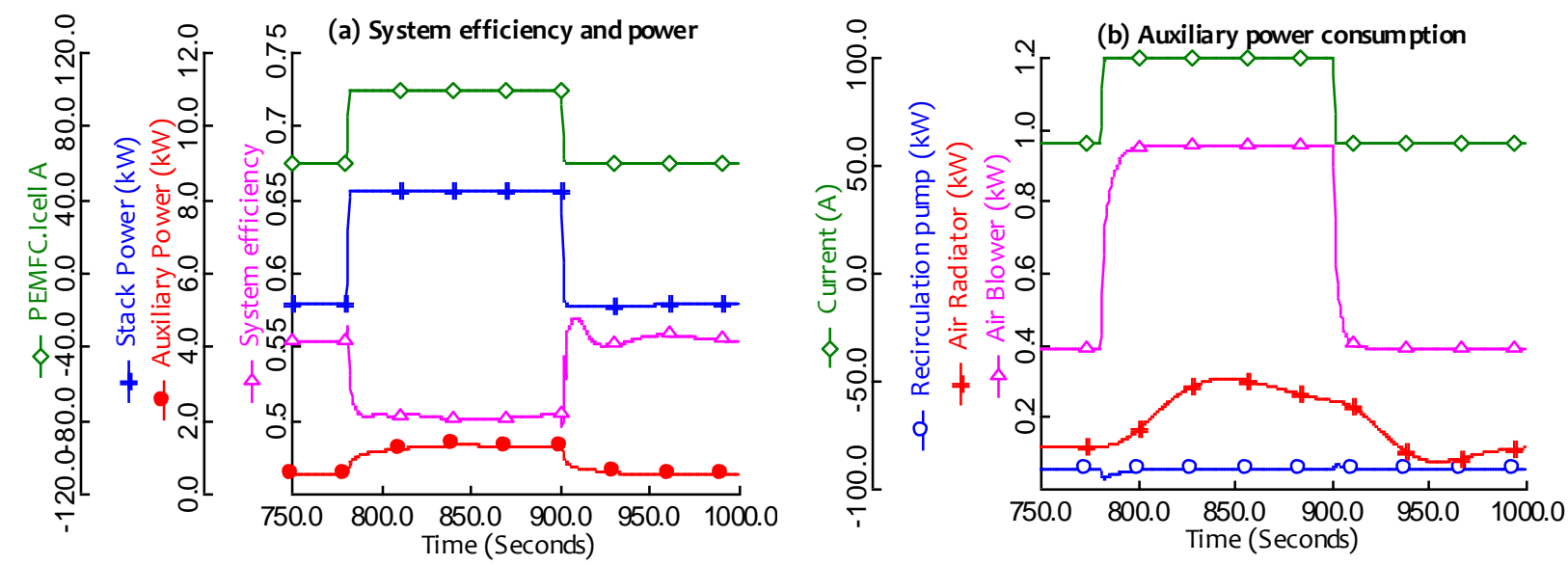

Figure 6. (a) System efficiency, stack power output and power consumed, and (b) Auxiliary power consumption.

On the other hand, at higher currents of $100 \mathrm{~A}$, power consumed by air blower and radiator constitutes $15 \%$ of the total stack power. For a swift temperature control and a thermally stable operation, air radiator requires more power or a larger heat exchanger area which would further reduce efficiency during these load variations. Power consumption of coolant pumps is not shown in the above figure because increase in internal and external coolant flows affects the auxiliary power consumption to a very small extent as compared to air compressor and radiator. Anode recirculation pump also consumes very low power; however the peaks at current surge are a noticeable detail, which is addressed later in the results.

\subsection{Effects of water transportation in fuel cell}

In PEMFCs, water management is a critical issue since the performance of fuel cell is strongly influenced by its internal water distribution. Figure 7a shows net water diffusion in the cell when current is changed from $60 \mathrm{~A}$ to $100 \mathrm{~A}$ and back. In the figure, positive values for water crossover designate transportation of water from cathode to anode of the fuel cell and vice versa. With 
increasing currents, more water is produced in the cathode which supports back-diffusion towards the anode until the system reaches back to steady-state and there is almost no net water crossover. Some negative peaks are also observed at the start of current change, which are due to electroosmotic drag. As more current is drawn, there is a rapid increase in hydrogen ion flux towards the cathode, thereby supporting water crossover through electro-osmotic drag. Back-diffusion rate is increased with the production of water on the cathode side and subsequently water flux is directed towards fuel cell anode. The reverse can said to be true when current is ramped down from $100 \mathrm{~A}$ to 60A.

Effect of water distribution can also be observed in anode inlet and outlet relative humidity. Whereas for the cathode, since it is assumed that air enters at a constant relative humidity of $95 \%$, the outlet humidity is always above $100 \%$. Therefore, results for only anode are discussed here.
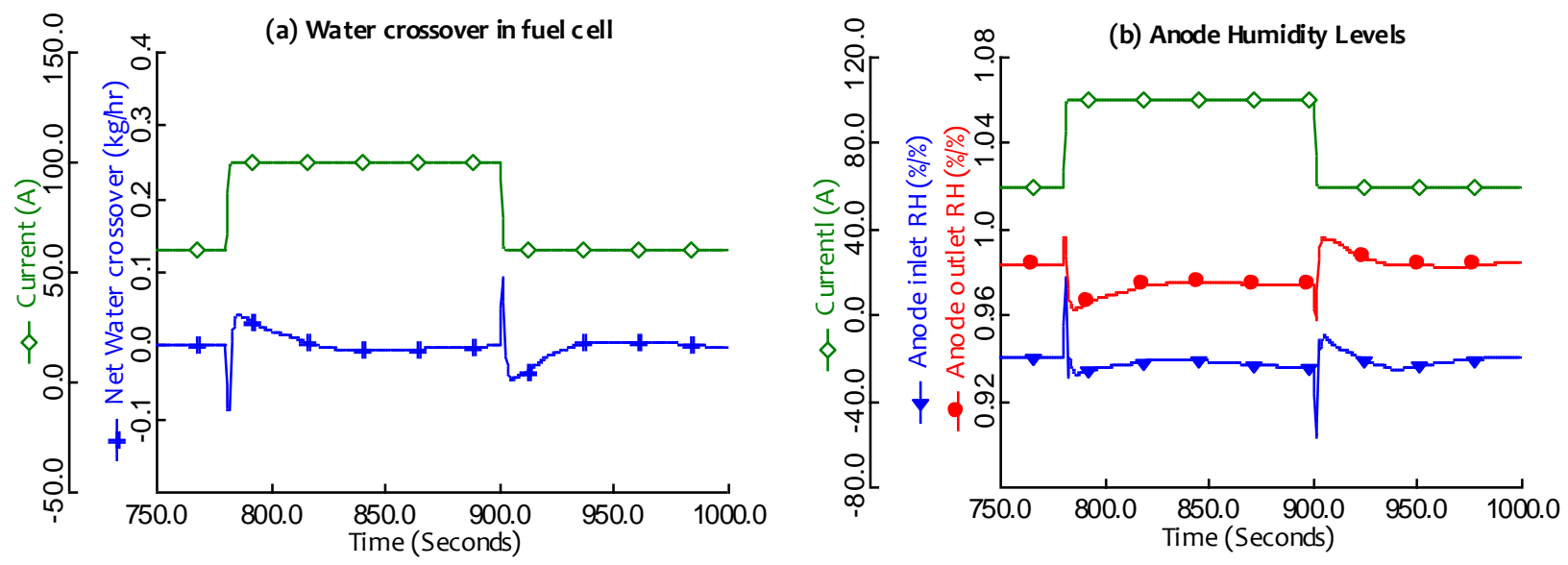

Figure 7. Current ramp-up from 60-100A and vice versa: (a) Water crossover through PEMFC membrane, (b) Effect of water transportation on anode $R H$.

From Fig. 7b, it could be further observed that relative humidity at anode outlet decreases with a current surge, though an abrupt increase is detected at the start of this change. Sudden ramping of the current consumes more hydrogen, leaving higher molar fraction and partial pressure of water in the anode, thus the peak of high relative humidity. With the rise in stack temperature, water activity on anode side is reduced and water diffusion from cathode increases and consequently stabilizes to almost zero net-water crossover with the control of operating temperature. As there is no external humidification apparatus for fuel and recirculation of anode exhaust aides in humidifying the anode, water crossover has a significant impact on anode operations which are discussed below.

\subsection{Fuel and oxidant flows}

Figure 8 depicts the variations in reactant inlet flows when the load on fuel cell is varied. It is interesting to notice the fluctuations in the anode inlet and outlet. When the current is ramped up from $60 \mathrm{~A}$ to $100 \mathrm{~A}$, more hydrogen is consumed increasing the utilization factor at that instance. This can be seen in Fig. 8b where mass flow at anode exhaust suddenly decreases. Changes in temperature can also be noted at these current surges as the air stream is cooled by external cooling circuit. 

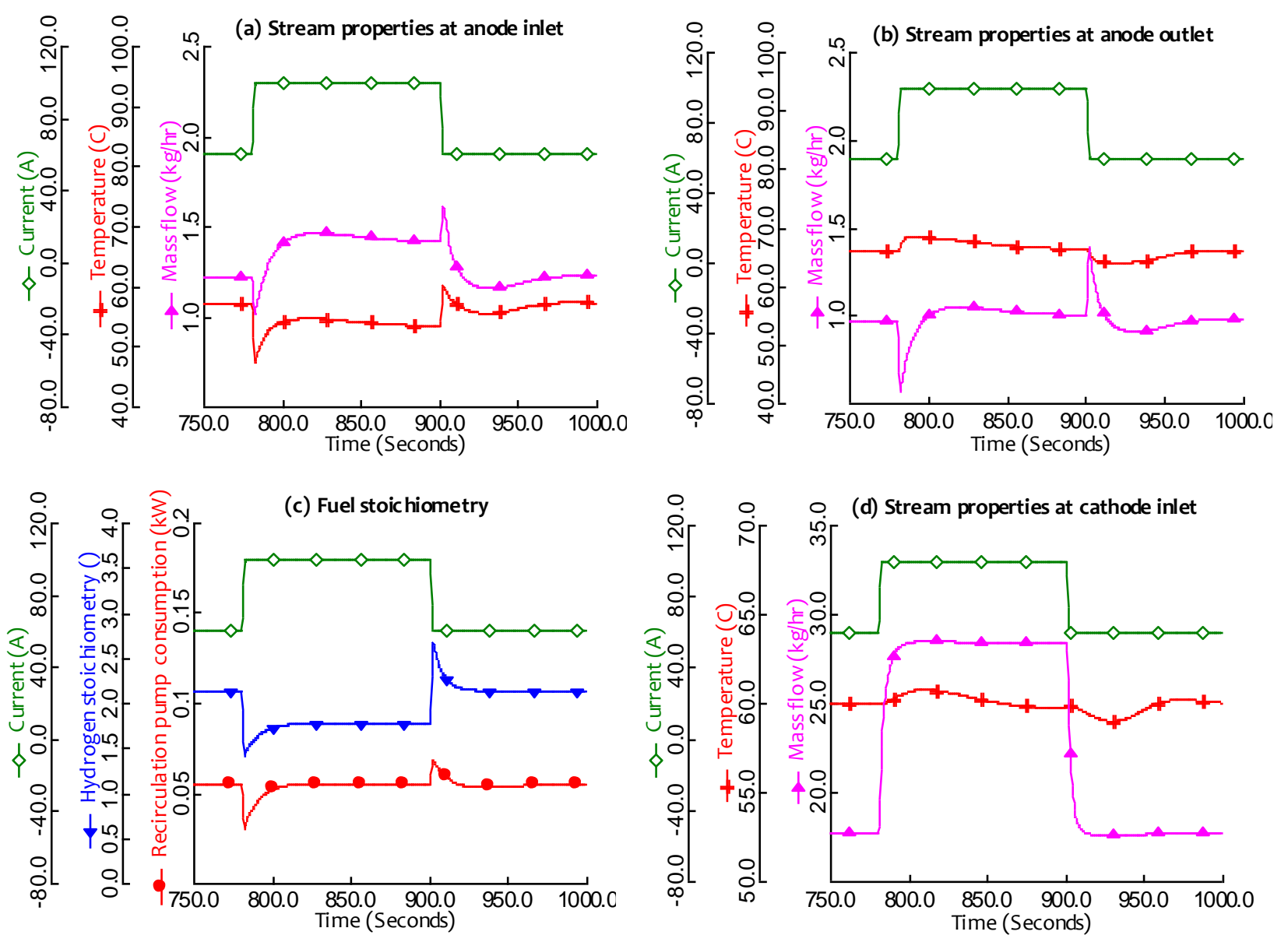

Figure 8. Current ramp-up from 60-100A and vice versa:, (a) Stream properties at anode inlet and (b) outlet respectively, (c) Effect on fuel stoichiometry and recirculation pump, (d) Air flow into the cathode.

Control of fuel stoichiometry takes some time to readjust to the desired level. Although, anode outlet flow is disturbed by fuel stoichiometry, it is also affected by the water content in anode outlet (70\% mass fraction), which depends on the net water crossover within the cell. Initial peaks at both load changes are also attributed to the electro-osmotic drag which is a function of current density. Since anode inlet is supported by recirculation from anode exhaust, the changes within the stack influence it considerably. In Fig. 8a, fuel flow at anode inlet follows a similar trend to that of anode exhaust, as well as the inlet temperature. Rapid reduction in temperature is due to lower volume of recirculation which is at around $69^{\circ} \mathrm{C}$ whereas dry hydrogen from the tank is at $25^{\circ} \mathrm{C}$. Fluctuations in water content at anode inlet disturb fuel flow controls and relative humidity constantly; they remain within acceptable ranges however. Figure $8 \mathrm{c}$ shows the fuel stoichiometry changes and power consumed by recirculation pump, which are affected by the depletion of hydrogen at anode cell sites and water diffusion during the current surges. On cathode side (Fig. 8d), as expected, the air flow which is regulated by a controller increases when the current is ramped up and steadies along with the system. There is no specific temperature control of inlet air in this model, though external coolant flows manipulate the air temperature which is further preheated by the humidifier before entering the stack. Air temperature varies around $60^{\circ} \mathrm{C}$ which is equal to the controlled temperature for coolant entering the stack; however temperature difference at anode inlet is significantly higher during these load variations. Such temperature gradients incur adverse effects as they form thermal stresses in the stack with co-flow configuration and reduce its life cycle. 


\subsection{Effects of water saturation at cathode}

Water removal from a fuel cell cathode is dependent on stack temperature and pressure drop. Temperature is more critical factor of the two, since at high temperature the water will be in vapour state and easier to remove. Stack water production increases with current and is also dependent on the number of cells. The exact amount of liquid water product depends on cathode outlet temperature. Inlet humidity also contributes to liquid water saturation in the fuel cell, as reported in Wong et al. [19]. Figure 9 provides information on the amount of liquid water at outlet of the cathode channel for two different current surge amplitudes.
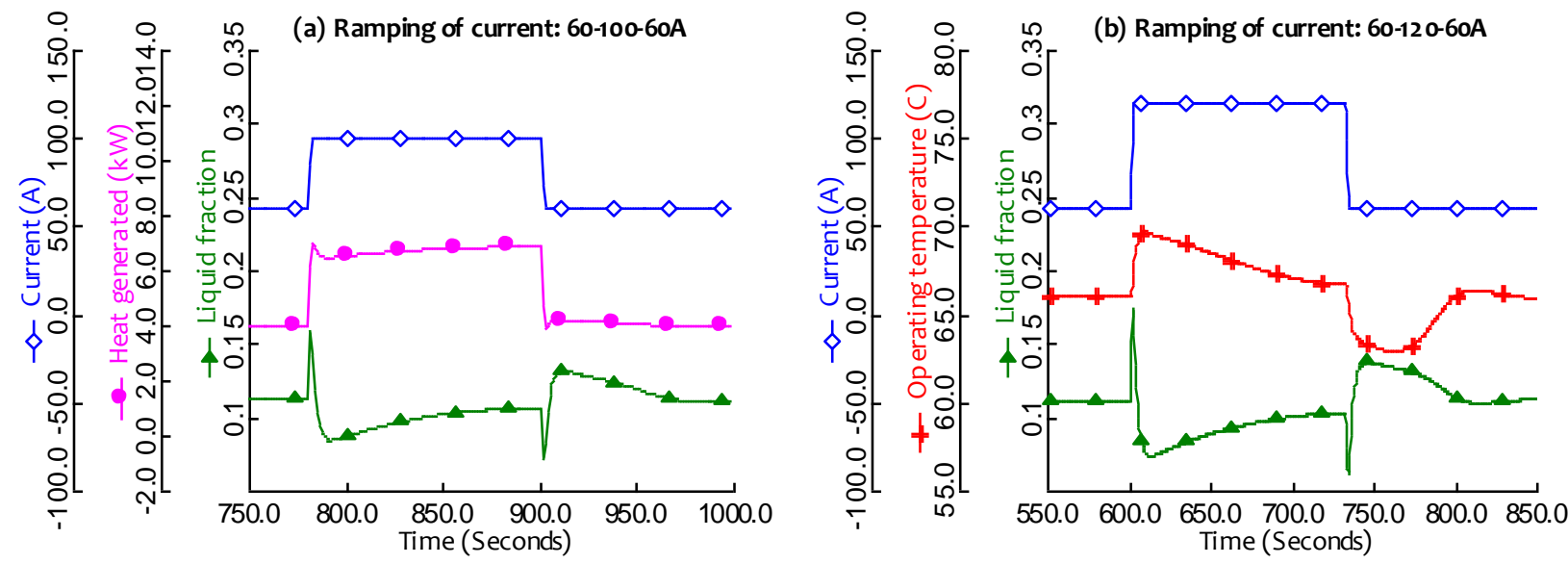

Figure 9. Water crossover through PEMFC membrane; (a) Current ramp-up from 60A to 100A and vice versa, (b) Current ramp-up from 60A to $120 \mathrm{~A}$ and back.

It can be seen in Fig. 9a, that there is an abrupt increase in amount of liquid water at cathode when the current is ramped from 60A to 100A. When higher currents are drawn, reactions within the fuel cell are accelerated which demand more intake of fuel and oxidant. Consequently these reactions produce more water when compared to production at low currents. Since the stack temperature does not elevate till that instance, higher percentage of produced water is saturated at fuel cell cathode. Heat produced by cell reactions then elevates the stack temperature, thereby reducing saturated water at the outlet. Moreover, condensation of water at cell sites produces additional heat which rapidly increases the stack temperature. It can be further noticed in Fig. 9a that heat produced in the stack lowers as water liquid fractions drop. On the other hand, when current is reduced back to 60A, a similar but opposite profile is observed and the amount of liquid water tends to increase with a sink in stack temperature. Therefore, at low temperatures and currents, water removal is a dominant factor and stoichiometries are determined by the minimum flow rates required for water removal which in the present case are more than adequate to provide the necessary concentrations. Figure $9 \mathrm{~b}$ shows water saturation results when ramping of current is set from $60 \mathrm{~A}$ to $120 \mathrm{~A}$ instead. Although the data profile is analogous to that of Fig. 9a, it is noted that amplitude of these peaks is higher when compared. Apparently, the amount of liquid water at cathode exit is same for both cases when the fuel cell is operating at steady state. Heat produced by condensation requires additional flow of coolant to maintain stack operating temperature, yet it does not affect the system efficiency to a greater extent as liquid pumps do not consume that much power. 


\section{Conclusions}

In this study, a comprehensive dynamic model of a PEMFC system along with the auxiliary components is presented and a substantial emphasis has been set to devise a control-oriented dynamic model of the fuel cell stack, which accommodates the electrochemical, thermal, feed flow and water transportation models. Main contributions of the proposed model are ascribed to the dynamic system responses, which is characterized mainly by heat management and water transportation within the fuel cell.

It is observed that thermal management strategy greatly influences voltage output and system efficiency which increase with stack operating temperature. Moreover, slow temperature controls affect the stability of fuel cell operations. In order to contemplate fast electrochemical changes in the stack, high coolant mass flow rates are applied. Power consumed by liquid coolant pumps is minimal and have no considerable effect on system efficiency, whereas air radiator consumes most of the power in thermal management system. Further, work is required on air radiator to ensure thermal stability of fuel cell operations and prolonged stack lifetime. A 5\% increase in power consumption of air blower and radiator is observed during load variations for the cases presented here.

Furthermore, water crossover in the fuel cell has shown a significant impact on PEMFC anode operations. Anode inlet flows, humidity and recirculation pump are influenced by net water diffusion during load changes. Temperature changes at anode inlet are considerably higher during load variations and have a negative impact as they generate thermal stresses in the stack and reduce its lifetime. Also, amount of saturated water at cathode is dependent on operating temperature which apparently pertains to thermal management strategy of the system. At low currents and temperatures, reactant stoichiometries are determined by the minimum flow rates required for water removal from the stack.

\section{Acknowledgement}

The authors would like to thank the Danish Energy Agency for financial support and our industrial partner, H2Logic, for their collaboration and technical support.

\section{References}

[1] J. C. Amphlett, R. F. Mann, B. A. Peppley, P. R. Roberge, A. Rodrigues, A model predicting transient responses of proton exchange membrane fuel cells, J. Power Sources 61(1996) 183188.

[2] S. Yerramalla, A. Davari, A. Feliachi, Dynamic modeling and analysis of polymer electrolyte fuel cell, IEEE Power Engineering Society Summer Meeting 1-3 (2002) 82-86.

[3] M. Ceraolo, C. Miulli, A. Pozio, Modelling static and dynamic behaviour of proton exchange membrane fuel cells on the basis of electro-chemical description, J. Power Sources 113 (2003) 131-144.

[4] J. T. Pukrushpan, H. Peng, A. G. Stefanopoulou, Control-Oriented Modeling and Analysis for Automotive Fuel Cel Systems, J. Dynamic Systems Measurement \& Control 126 (2004) $14-25$. 
[5] P. R. Pathapati, X. Xue, J. Tang, A new dynamic model for predicting transient phenomena in a PEM fuel cell system, Renewable Energy 30 (2005) 1-22.

[6] G. Hu, J. Fan, S. Chen, Y. Liu, K. Cen, Three-dimensional numerical analysis of proton exchange membrane fuel cells (PEMFCs) with conventional and interdigitated flow fields, J. Power Sources 136 (2004) 1-9.

[7] S.K. Park , S.Y. Choe, Dynamic modeling and analysis of a 20-cell PEM fuel cell stack considering temperature and two-phase effects, J. Power Sources 179 (2008) 660-672.

[8] J. Jia, Y. Wang, Q. Li, Y. T. Cham, M. Han, Modeling and Dynamic Characteristic Simulation of a Proton Exchange Membrane Fuel Cell, IEEE Transactions on Energy Conversion 24 (2009) 283-291.

[9] G. Vasu, A. K. Tangirala, Control-orientated thermal model for proton-exchange membrane fuel cell systems, J. Power Sources 183 (2008) 98-108.

[10] M. J. Khan, M. T. Iqbal, Modelling and analysis of electrochemical, thermal, and reactant flow dynamics for a PEM fuel cell system, Fuel Cells 5 (2005) 463-475.

[11] Y. Shan, S.Y. Choe, Modeling and simulation of a PEM fuel cell stack considering temperature effects, J. Power Sources 158 (2006) 274-286.

[12] A. J. del Real, A. Arce, C. Bordons, Development and experimental validation of a PEM fuel cell dynamic model, J. Power Sources 173 (2007) 310-324.

[13] J.W. Ahn, S.Y. Choe, Coolant controls of a PEM fuel cell system, J. Power Sources 179 (2008) 252-264.

[14] J.H. Jung, S. Ahmed, Dynamic model of PEM fuel cell using real-time simulation techniques, J. Power Electronics 10 (2010) 739-748.

[15] S. Asghari, H. Akhgar, B. F. Imani, Design of thermal management subsystem for a 5kW polymer electrolyte membrane fuel cell system, J. Power Sources 196 (2011) 3141-3148.

[16] A. Beicha, Modeling and simulation of proton exchange membrane fuel cell systems, J. Power Sources 205 (2012) 335-339.

[17] Ballard Mark9 SSL, Product manual and integration guide 2008.

[18] E. Hosseinzadeh, M. Rokni, Development and validation of a simple analytical model of the Proton Exchange Membrane Fuel Cell (PEMFC) in a fork-lift truck power system, Intl. J. Green Energy, In Press (2012) DOI: 10.1080/15435075.2012.678525.

[19] K. H. Wong, K. H. Loo, Y. M. Lai, S.-C. Tan, C. K. Tse, A theoretical study of inlet relative humidity control in PEM fuel cell, Intl. J. Hydrogen Energy 36 (2011) 11871-11885. 


\section{Nomenclature}

E theoretical voltage $(V)$

$V_{\text {cell }} \quad$ average cell voltage $(V)$

$\dot{P}_{e l} \quad$ stack power $(k W)$

$\dot{P}_{i n} \quad$ energy into the fuel cell $(k W)$

$\dot{P}_{\text {out }} \quad$ energy out of the fuel cell $(k W)$

$\dot{Q}_{\text {loss }} \quad$ heat dissipated $(k W)$

$C_{t} \quad$ stack thermal capacitance $(k W)$

$R \quad$ universal gas constant $(\mathrm{J} / \mathrm{molK})$

$T \quad$ temperature $(K)$

$F \quad$ Faraday's constant $(C / m o l K)$

I current $(A)$

$N_{\text {cell }} \quad$ number of cells $(-)$

$\Delta \bar{g}_{f}^{0} \quad$ change in Gibbs free energy $(\mathrm{J} / \mathrm{molK})$

$P_{H_{2}} \quad$ hydrogen partial pressure (-)

$P_{\mathrm{O}_{2}} \quad$ oxygen partial pressure (-)

$M_{m} \quad$ mol. weight of membrane $(\mathrm{Kg} / \mathrm{mol})$

$\mathrm{J}_{\mathrm{H}_{2} \mathrm{O}} \quad$ net water-diffusion flux $\left(\mathrm{mol} / \mathrm{scm}^{2}\right)$

$D_{\lambda} \quad$ water diffusion coefficient $\left(\mathrm{cm}^{2} / \mathrm{s}\right)$

$a_{H_{2}} \quad$ hydrogen activity $(-)$

$a_{\mathrm{H}_{2} \mathrm{O}} \quad$ water activity $(-)$

$a_{\mathrm{O}_{2}} \quad$ oxygen activity $(-)$

$i \quad$ current density $\left(A / \mathrm{cm}^{2}\right)$

$i_{n} \quad$ internal current density $\left(A / \mathrm{cm}^{2}\right)$

$i_{0} \quad$ exchange current density $\left(A / \mathrm{cm}^{2}\right)$

$i_{0, a} \quad$ anode exchange current density $\left(A / \mathrm{cm}^{2}\right)$

$i_{0, c} \quad$ cathode exchange current density $\left(A / \mathrm{cm}^{2}\right)$

$k_{a} \quad$ anode reaction rate $\left(\mathrm{mol} / \mathrm{scm}^{2}\right)$

$k_{c} \quad$ cathode reaction rate $\left(\mathrm{mol} / \mathrm{scm}^{2}\right)$

$n_{e} \quad$ electrons transferred $\left(\operatorname{mol}_{e} / m_{\text {fuel }}\right)$

$n_{e l} \quad$ number of electrons $(-)$

$n_{\text {drag }} \quad$ electro osmotic drag $(-)$

$t_{m} \quad$ membrane thickness $(\mathrm{cm})$

\section{Greek symbols}
$\alpha_{a} \quad$ anode transfer coefficient $(-)$
$\alpha_{c} \quad$ cathode transfer coefficient $(-)$
$\beta \quad$ symmetry factor $(-)$
$\eta_{\text {act }} \quad$ activation overpotential $(V)$ 
$\eta_{a c t, a} \quad$ anode activation overpotential $(V)$

$\eta_{a c t, c} \quad$ cathode activation overpotential $(V)$

$\eta_{\text {conc }} \quad$ concentration overpotential $(V)$

$\eta_{\text {ohmic }} \quad$ ohmic overpotential $(V)$

$\lambda \quad$ membrane water content $(-)$

$\rho_{d r y} \quad$ membrane density $\left(\mathrm{g} / \mathrm{cm}^{3}\right)$ 